\title{
Programmed changes in the adult rat offspring caused by maternal protein restriction during gestation and lactation are attenuated by maternal moderate-low physical training
}

\author{
Marco Fidalgo ${ }^{1}$, Filippe Falcão-Tebas ${ }^{2}$, Adriano Bento-Santos ${ }^{2}$, Elaine de Oliveira ${ }^{3}$, \\ José Firmino Nogueira-Neto ${ }^{3}$, Egberto Gaspar de Moura ${ }^{3}$, Patrícia Cristina Lisboa ${ }^{3}$, \\ Raul Manhães de Castro ${ }^{2}$ and Carol Góis Leandro ${ }^{1 *}$ \\ ${ }^{1}$ Department of Physical Education and Sports Science, CAV, Federal University of Pernambuco, Pernambuco, Brazil \\ ${ }^{2}$ Department of Nutrition, Federal University of Pernambuco, Pernambuco, Brazil \\ ${ }^{3}$ Department of Physiological Sciences, Roberto Alcantara Gomes Biology Institute, State University of Rio de Janeiro, \\ Rio de Janeiro, Brazil
}

(Submitted 1 July 2011 - Final revision received 3 March 2012 - Accepted 5 March 2012 - First published online 1 May 2012)

\section{Abstract}

The effects of maternal moderate-low physical training on postnatal development, glucose homeostasis and leptin concentration in adult offspring subjected to a low-protein diet during the perinatal period were investigated. Male Wistar rats (aged $150 \mathrm{~d}$ old) were divided into four groups according to maternal group: untrained $\left(\mathrm{NT}_{\mathrm{p}}, n 8\right)$; trained $\left(\mathrm{T}_{\mathrm{p}}, n 8\right)$; untrained with a low-protein diet $\left(\mathrm{NT}+\mathrm{LP}_{\mathrm{p}}, n 8\right)$; trained with a low-protein diet $\left(\mathrm{T}+\mathrm{LP}_{\mathrm{p}}, n 8\right)$. The trained mothers were subjected to a protocol of moderate physical training over a period of 4 weeks (treadmill, $5 \mathrm{~d} /$ week, $60 \mathrm{~min} / \mathrm{d}$, at $65 \% \mathrm{VO}_{2 \max }$ ) before mating. At pregnancy, the intensity and duration of exercise was progressively reduced $\left(50-20 \mathrm{~min} / \mathrm{d}\right.$, at $\left.65-30 \% \mathrm{VO}_{2 \max }\right)$. The low-protein diet groups received an $8 \%$ casein diet, and their peers received a $17 \%$ casein diet during gestation and lactation. The pups' birth weight and somatic growth were recorded weekly up to the 150 th day. Fasting blood glucose, cholesterol, serum leptin concentration, glucose and insulin tolerance tests were evaluated. The $\mathrm{T}_{\mathrm{p}}$ animals showed no changes in somatic and biochemical parameters, while the $\mathrm{NT}+\mathrm{LP}_{\mathrm{p}}$ group showed a greater abdominal circumference, hyperglycaemia, hypercholesterolaemia, glucose intolerance and lower plasma leptin. In the $\mathrm{T}+\mathrm{LP}_{\mathrm{p}}$ animals, all of those alterations were reversed except for plasma leptin concentration. In conclusion, the effects of a perinatal low-protein diet on growth and development, glucose homeostasis and serum leptin concentration in the offspring were attenuated in pups from trained mothers.

Key words: Glucose homeostasis: Gestational exercise: Developmental plasticity: Perinatal undernutrition

The peri- and preconception periods are now thought to be critical for the long-term effects on fetal development and postnatal growth and may predispose offspring to phenotypic changes and metabolic diseases later in life ${ }^{(1)}$. Unbalanced nutrient intake during this critical period of development has been associated with subsequent health risks and disease in the offspring, according to epidemiological data and numerous experimental observations ${ }^{(2)}$. This phenomenon has been termed 'developmental plasticity'(3). Developmental plasticity is the property of a given genotype to produce different phenotypes in response to distinct environmental conditions $^{(4)}$.

The maternal low-protein diet model is one of the most extensively studied models of early growth restriction ${ }^{(5)}$ A low-protein diet ( $8 \%$ casein) during gestation followed by a normal diet throughout the life course has been associated with growth restriction, slightly elevated systolic blood pressure and increased fasting plasma insulin concentrations compared with control offspring ${ }^{(5)}$. If maternal protein restriction is continued during lactation, there is lasting growth

Abbreviations: BWG, body-weight gain; GTT, glucose tolerance test; ITT, insulin tolerance test; LP, low-protein rats; NT, untrained rats; NT $\mathrm{p}$, pups of untrained rats; $\mathrm{NT}+\mathrm{LP}$, untrained rats with a low-protein diet; $\mathrm{NT}+\mathrm{LP}_{\mathrm{p}}$, pups of untrained rats with a low-protein diet; $\mathrm{T}$, trained rats; $\mathrm{T}_{\mathrm{p}}$, pups of trained rats; TBS-T, mixture of Tris-buffered saline and Tween 20; T $+\mathrm{LP}$, trained rats with a low-protein diet; $\mathrm{T}+\mathrm{LP} \mathrm{p}_{\mathrm{p}}$, pups of trained rats with a lowprotein diet.

*Corresponding author: C. G. Leandro, fax +5581 35233351, email carolleandro22@gmail.com 
restriction, age-dependent loss of glucose tolerance, insulin resistance, hypertension and hyperleptinaemia, even when the offspring are weaned onto a control diet ${ }^{(5)}$. In adult rats (110 d) subjected to a low-protein diet (10\% casein) during pregnancy and lactation, Zambrano et al. ${ }^{(6)}$ observed a lower serum leptin concentration. Leptin is a hormone mainly produced by adipocytes; however, it is also produced by several tissues, including skeletal muscle ${ }^{(7)}$. The presence of leptin in the muscle could be indicative of adipocyte infiltration, or leptin may have been produced directly by muscle fibres ${ }^{(8)}$.

Recently, we demonstrated that controlled moderate- to lowintensity physical training before and during gestation attenuated the impact of the low-protein diet by improving the mothers' resting oxygen consumption and the growth rate of the offspring ${ }^{(9)}$. In addition, physical exercise training has been associated with a reduced risk of metabolic disease and enhances both cardiorespiratory and metabolic functions. During gestation, the beneficial effects of physical exercise are dependent on the volume of exercise ${ }^{(9)}$. There are different physiological responses according to the type and frequency of exercise, the physical fitness of the mother, the time point in pregnancy when the exercise is carried out and the duration and intensity of exercise ${ }^{(10,11)}$. In 2002, the American College of Obstetricians and Gynecologists published exercise guidelines for pregnancy ${ }^{(12)}$. In these recommendations, it was suggested that after medical approval, $30 \mathrm{~min}$ or more of moderate exercise a day on most, if not all, days of the week is recommended for pregnant women. Exercise is considered moderate when oxygen consumption is approximately $50-70 \%$ of $\mathrm{VO}_{2 \max }$. Regular practice of moderate exercise has been associated with improved cardiorespiratory fitness, increased metabolic rate (reduction in body weight) and increased muscle mitochondrial biogenesis ${ }^{(13)}$. At rest, the rate of placental red blood flow increases, and more glucose and oxygen delivery to the placental site are observed in women subjected to a physical training regimen ${ }^{(11)}$. An epidemiological study found that moderate physical exercise during pregnancy is associated with a $100-150 \mathrm{~g}$ increase in birth weight ${ }^{(14)}$.

Little is known about the long-term effects of maternal physical activity on adult offspring subjected to perinatal undernutrition. This is a topic of particular interest as a maternal lifestyle can be considered a therapeutic means of countering the effects of either maternal undernutrition or overnutrition. Thus, in the present study, the effects of a maternal moderate-low protocol of physical training on postnatal development, glucose homeostasis and leptin concentration in adult offspring whose mothers were subjected to a low-protein diet during the perinatal period were investigated. Our hypothesis is that exercise-induced physiological adaptations during gestation, as seen in our previous studies, attenuate or modulate the impact of a perinatal low-protein diet on glucose homeostasis and leptin concentrations in adult offspring.

\section{Materials and methods}

The experimental protocol was approved by the Ethical Committee of the Biological Sciences Centre (protocol no. 80
23 076.049077/2010-80), Federal University of Pernambuco, Brazil and followed the Guidelines for the Care and Use of Laboratory Animals ${ }^{(15)}$.

\section{Animals}

Virgin female albino Wistar rats (Rattus norvegicus) aged $60 \mathrm{~d}$ were obtained from the Department of Nutrition, Federal University of Pernambuco, Brazil. Female rats were maintained at a room temperature of $23 \pm 2{ }^{\circ} \mathrm{C}$ with a controlled light-dark cycle (dark 09.00-21.00 hours). Standard laboratory chow $(52 \%$ carbohydrate, $21 \%$ protein and $4 \%$ lipids; Agribrands-Purina Limited) and water were given ad libitum. The animals were randomly divided into two groups: untrained rats $(n 8)$ and trained rats $(n 8)$. The trained rats were subjected to a training programme of moderate running over a period of 4 weeks $(5 \mathrm{~d} /$ week and $60 \mathrm{~min} / \mathrm{d})$ on a treadmill (EP-131; Insight Equipments) at a controlled intensity based on their $\mathrm{VO}_{2 \max }{ }^{(9)}$. After the 4 -week training period, the rats were mated (two females for one male). The day on which spermatozoa were present in a vaginal smear was designated as the day of conception, day 0 of pregnancy. Pregnant rats were then transferred to individual cages. Half of the rats from each group received a $17 \%$ casein diet, and the other half received an $8 \%$ casein isoenergetic diet (lowprotein group, LP) ${ }^{(16)}$ ad libitum. Thus, two more groups were formed, which are as follows: untrained (NT, $n$ 4); trained (T, $n 4)$; untrained with a low-protein diet $(\mathrm{NT}+\mathrm{LP}$, $n$ 4); trained with a low-protein diet (T $+\mathrm{LP}, n$ 4). The exercise programme was maintained during gestation, with a progressive reduction in duration and intensity until the 19th day of gestation. There was no physical exercise during the suckling period. During lactation, the offspring were kept in litters of six pups, and their mothers continued to be fed with the $8 \%$ casein or $17 \%$ casein diet. Only male offspring from each litter were used. In all subsequent experiments, two male offspring were randomly chosen from each litter. The pups were divided into four groups according to their mothers' assigned group: untrained $\left(\mathrm{NT}_{\mathrm{p}}, n 8\right)$; trained $\left(\mathrm{T}_{\mathrm{p}}, n 8\right)$; untrained with a low-protein $\operatorname{diet}\left(\mathrm{NT}+\mathrm{LP}_{\mathrm{p}}, n 8\right)$; trained with a low-protein diet $\left(\mathrm{T}+\mathrm{LP}_{\mathrm{p}}, n 8\right)$. At $150 \mathrm{~d}$ of age, pups were killed by cardiac exsanguination.

\section{Physical training protocol}

Physical training was performed according to Amorim et al. ${ }^{(9)}$. Briefly, rats ran on a treadmill during the 4 weeks $(5 \mathrm{~d} /$ week, $60 \mathrm{~min} / \mathrm{d}$, at $65 \% \mathrm{VO}_{2 \max }$ ) before pregnancy. The protocol was divided into four progressive stages in each session: (1) warm-up ( $5 \mathrm{~min})$; (2) intermediary (10 min); (3) training ( $30 \mathrm{~min})$; (4) cool-down $(5 \mathrm{~min})$. The percentage of $\mathrm{VO}_{2 \max }$ during the sessions of training before gestation was kept at approximately 55-65\%. During pregnancy, rats ran ( $5 \mathrm{~d} /$ week) at a progressively reduced duration and intensity of effort (first week $50 \mathrm{~min} / \mathrm{d}$ (approximately $65 \%$ of $\mathrm{VO}_{2 \max }$ ), second week $30 \mathrm{~min} / \mathrm{d}$ (approximately $45 \%$ of $\mathrm{VO}_{2 \max }$ ) and third week $20 \mathrm{~min} / \mathrm{d}$ (approximately $32 \%$ of $\mathrm{VO}_{2 \max }$ )). There was no physical training during the lactation period. 


\section{Measurement of food intake and body weight during} gestation

During gestation, dams were housed individually, and their daily food consumption was determined by the difference between the amount of food provided at the onset of the light cycle and the amount of food remaining $24 \mathrm{~h}$ later ${ }^{(17)}$. Body and food weights were recorded to the nearest $0.01 \mathrm{~g}$. Body weight was recorded daily throughout the experiment by a Marte Scale (AS-1000; Marte Científica) approaching $0 \cdot 01 \mathrm{~g}$. Percentage of weight gain ( $\% \mathrm{BWG}$ ) was calculated by the formula:

$$
\begin{aligned}
\% \mathrm{BWG}= & (\text { body weight }(\mathrm{g}) \\
& \times 100 / \text { weight at the first day of gestation }(\mathrm{g}))-100 .
\end{aligned}
$$

\section{Blood glucose measurements}

Fasting glycaemia levels were evaluated weekly during gestation using blood samples from the tail vein of rats, using a glucometer (Accu Check Advantage and Roche) and the glucose oxidase method. The animals were fasted overnight.

\section{Postnatal developmental patterns of offspring}

The body weights of pups were recorded weekly throughout the experiment with a Marte Scale (AS-1000) approaching $0.01 \mathrm{~g}$. Percentage of weight gain (\%BWG) was calculated at different intervals of time until $150 \mathrm{~d}$ old (birth to 30th, 31 st to 90 th and 91 st to 150 th) by the formula:

$\% \mathrm{BWG}=$ (body weight $(\mathrm{g})$ $\times 100 /$ weight at the first day in the interval $(g))-100$.

The body lengths of pups were recorded by measuring the external surfaces (nose-to-anus length) using a digital calliper $(0.01 \mathrm{~mm}$ accuracy). Body weight and body length were used to determine BMI (weight $(\mathrm{g}) /$ length $\left.(\mathrm{cm})^{2}\right)^{(18)}$. Abdominal circumference was recorded by measuring the midpoint between the lower rib margin and the iliac crest in the horizontal plane ${ }^{(18)}$

\section{Glucose tolerance test and insulin tolerance test of offspring}

The glucose tolerance test (GTT) was performed at $145 \mathrm{~d}$ and the insulin tolerance test (ITT) at $147 \mathrm{~d}$ of age. In both tests, animals were fasted overnight. Blood sample collections were performed by cutting the tip of the tail to remove approximately $10 \mu \mathrm{l}$ of blood. The first blood sample was collected (time zero) before the injection of glucose. In the GTT, a $50 \%$ glucose solution (Equiplex Pharmaceutical Limited) at a dose of $1 \mathrm{mg} / \mathrm{g}$ body weight was administered intraperitoneally. Blood samples were then collected at 15, 30, 45, 60 and $120 \mathrm{~min}$ after administration. The area under the glucose curve was obtained by blood glucose values at 0, 30, 60 and
120 min using the trapezoidal method ${ }^{(19)}$. In the ITT, a solution of insulin (Eli Lilly do Brazil Limited) at a dose of $0.75 \mathrm{mU}(34.125 \mathrm{ng}) / \mathrm{g}$ body weight was administered intraperitoneally, and additional blood samples were collected at 15 ,
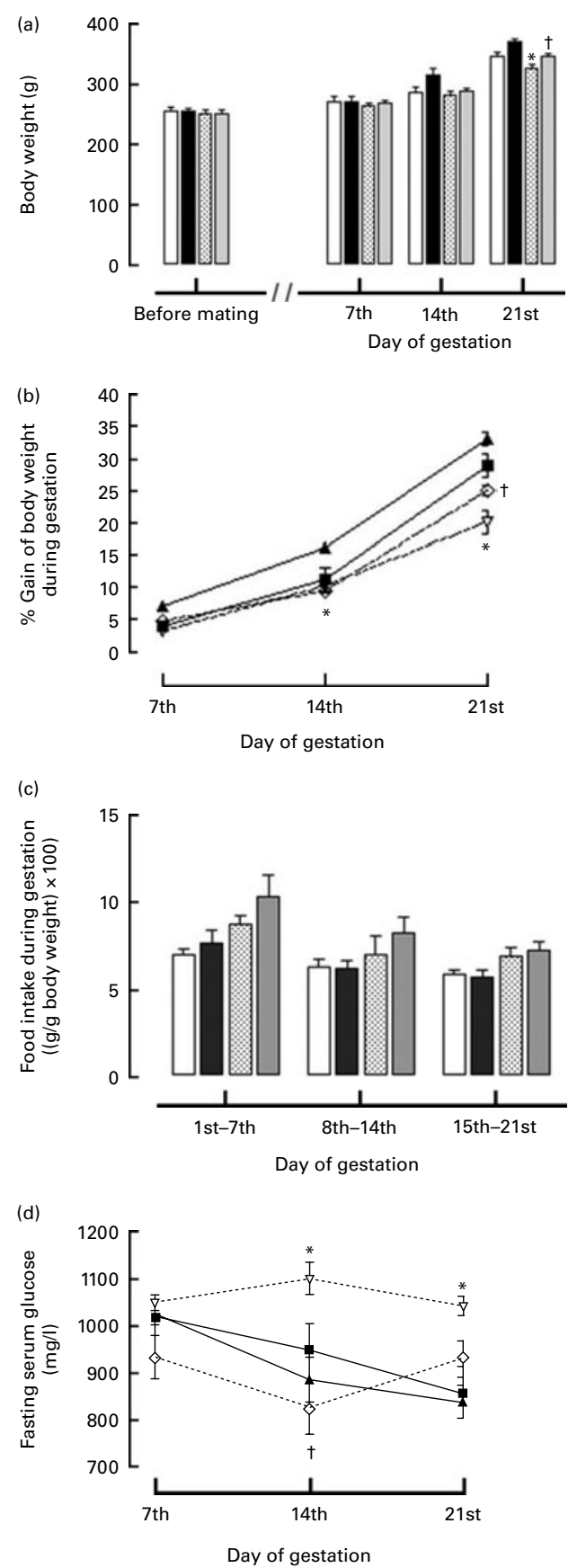

Fig. 1. (a) Body weight (g), (b) percentage of body-weight gain in each third week of gestation, relative to the body mass on the first day of pregnancy, (c) relative daily food intake expressed in $\mathrm{g} / \mathrm{d}$ during gestation and (d) fasting blood glucose by non-trained (NT, $n$ 4; (a, c) $\square$ and (b, d) $-\mathrm{-}$ ), trained $(\mathrm{T}, n$ 4; $(\mathrm{a}, \mathrm{c}) \mathbf{\square}$ and (b, d) $\mathbf{-}$ ), non-trained + low-protein (NT + LP, $n$ 4; $(\mathrm{a}, \mathrm{c})$ and $(\mathrm{b}, \mathrm{d}) \cdot \nabla \cdot)$ and trained + low-protein $(\mathrm{T}+\mathrm{LP}, n 4 ;(\mathrm{a}, \mathrm{c}) \square$ and $(b, d) \cdot \odot$ ) dams. Values are means with their standard errors represented by vertical bars. * Mean values were significantly different from the NT group $(P<0.05$; two-way ANOVA). † Mean values were significantly different from the NT + LP group $(P<0.05$; two-way ANOVA). 
30, 45, 60 and $120 \mathrm{~min}$. Glucose disappearance constant was calculated from the blood glucose values obtained at 0,30 and $60 \mathrm{~min}(\mathrm{Kitt})^{(19)}$.

\section{Resting blood glucose, cholesterol and leptin}

At $150 \mathrm{~d}$ old, animals were anaesthetised with ketamine $(0.25 \mathrm{ml} / 100 \mathrm{~g}$ body weight $)$ and xylazine $(0.25 \mathrm{ml} / 100 \mathrm{~g}$ body weight). Blood was sampled by cardiac puncture for the quantification of overnight fasting serum glucose, cholesterol and leptin concentrations. Glycaemia and cholesterolaemia were determined in blood samples using a glucometer and a cholesterol meter (Accu Check Advantage and Accutrend GCT; Roche Diagnostics Limited), respectively. Plasma leptin concentration was determined by a RIA kit (Linco Research, Inc.), with an assay sensitivity of $0.5 \mathrm{ng} / \mathrm{ml}$ and an intra-assay variation coefficient of $2 \cdot 9 \%$. The samples were analysed in one assay.

\section{Western blotting for leptin content analysis}

The soleus muscle (right) was weighed and homogenised in

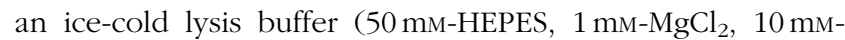
EDTA, Triton X-100 1\%, pH 6.4) and protease inhibitor cocktail $(1 \mathrm{mg} / \mathrm{ml}$ aprotinin, leupeptin and phenylmethylsulfonyl fluoride; Sigma-Aldrich, Inc.). Total protein content of the supernatants was determined by the bicinchoninic acid method (Protein Assay Kit; Thermo Fisher Scientific, Inc.).
Samples with $10 \mu \mathrm{g}$ total protein were separated by SDSPAGE (12\%) and transferred to a nitrocellulose membrane (Hybond P; Amersham Pharmacia Biotech, Inc.). Membranes were blocked for $90 \mathrm{~min}$ with $5 \%$ non-fat dry milk in TBS-T (20 mm-Tris, $0 \cdot 5 \mathrm{M}-\mathrm{NaCl}$ and $0 \cdot 1 \%$ Tween 20 ). The membranes were then washed three times with T-TBS and incubated overnight with primary antibody anti-leptin (rabbit monoclonal 1:1000; Sigma Chemical Company). They were then washed and incubated for $1 \mathrm{~h}$ with secondary antibody anti-rabbit (goat anti-rabbit conjugated with horseradish peroxidase 1:1000; Santa Cruz Biotechnology, Inc.). After the membranes had been washed three times with T-TBS, antibody binding was visualised using 3,3-diaminobenzidine tetrahydrochloride (10 $\mathrm{mg}$ in $15 \mathrm{ml}$ Tris buffer, $0 \cdot 1 \mathrm{M}, \mathrm{pH} 7 \cdot 4$ ). Images were scanned, and the bands were quantified by densitometry using Image J (Cibernetics Media, Inc.).

\section{Statistical analysis}

Results are presented as means with their standard errors. Intra-litter analyses were performed and found not to be significant. For statistical analysis, data were analysed by two-way repeated-measures ANOVA, with mothers' diet (NT and $\mathrm{NT}+\mathrm{LP})$ and physical training (T and T $+\mathrm{LP})$ as factors. Pearson's correlation coefficient was used to correlate body-weight gain with the number of pups born per mother. Significance was set at $P<0 \cdot 05$. Data analysis was performed using the statistical program Graphpad Prism $5^{\circledR}$ (GraphPad Software, Inc.).

Table 1. Body weight, body length, BMl and abdominal circumference of the offspring at $30,60,90,120$ and $150 \mathrm{~d}$ old $\neq$ (Mean values with their standard errors)

\begin{tabular}{|c|c|c|c|c|c|c|c|c|c|}
\hline & \multirow[b]{3}{*}{ Ages (d) } & \multicolumn{8}{|c|}{ Groups } \\
\hline & & \multicolumn{2}{|c|}{$\mathrm{NT}_{\mathrm{p}}(n \mathrm{8})$} & \multicolumn{2}{|c|}{$\mathrm{T}_{\mathrm{p}}(n 8)$} & \multicolumn{2}{|c|}{$\mathrm{NT}+\mathrm{LP}_{\mathrm{p}}(n 8)$} & \multicolumn{2}{|c|}{$\mathrm{T}+\mathrm{LP}_{\mathrm{p}}(n$ 8) } \\
\hline & & Mean & SEM & Mean & SEM & Mean & SEM & Mean & SEM \\
\hline \multirow[t]{6}{*}{ Body weight (g) } & Birth & $6 \cdot 2$ & 0.1 & $6 \cdot 2$ & 0.1 & $4.8^{*}$ & 0.08 & $5 \cdot 1$ & 0.06 \\
\hline & 30 & $86 \cdot 1$ & $2 \cdot 1$ & 80.0 & 2.5 & $38.8^{*}$ & $2 \cdot 1$ & 48.6 & 2.5 \\
\hline & 60 & 258.8 & $5 \cdot 6$ & $249 \cdot 2$ & $7 \cdot 7$ & $188 \cdot 6^{\star}$ & 3.4 & $232.9 \dagger$ & 5.5 \\
\hline & 90 & 351.4 & $8 \cdot 8$ & 342.5 & $7 \cdot 3$ & 284. $9^{\star}$ & $9 \cdot 4$ & $329.3 \dagger$ & 11.7 \\
\hline & 120 & 393.1 & 9.9 & $386 \cdot 6$ & $10 \cdot 1$ & $289 \cdot 3^{*}$ & $5 \cdot 3$ & $372.4 \dagger$ & $4 \cdot 8$ \\
\hline & 150 & $421 \cdot 8$ & $8 \cdot 6$ & $449 \cdot 3$ & 3.5 & $343 \cdot 2^{*}$ & $11 \cdot 3$ & $398.5 \dagger$ & 1.5 \\
\hline \multirow[t]{3}{*}{ \% BWG } & Birth-30 & $1388 \cdot 7$ & $102 \cdot 1$ & $1187 \cdot 2$ & $112 \cdot 2$ & $708.9^{\star}$ & 41.9 & $852 \cdot 2$ & $51 \cdot 1$ \\
\hline & $31-90$ & 309,1 & 10.5 & $328 \cdot 3$ & $15 \cdot 9$ & $641 \cdot 1^{*}$ & 19.9 & $494.5 \dagger$ & $15 \cdot 2$ \\
\hline & $91-150$ & 20,9 & 3.7 & $30 \cdot 3$ & 4.4 & 20.5 & 4.4 & $21 \cdot 0$ & 4.4 \\
\hline \multirow[t]{5}{*}{ Body length $(\mathrm{cm})$} & 30 & $14 \cdot 7$ & 0.2 & 14.1 & 0.12 & $12 \cdot 3^{*}$ & $0 \cdot 18$ & $12 \cdot 6$ & $0 \cdot 16$ \\
\hline & 60 & $20 \cdot 3$ & 0.2 & 19.7 & 0.23 & $18 \cdot 3^{\star}$ & 0.18 & $19.5 \dagger$ & 0.22 \\
\hline & 90 & $21 \cdot 3$ & 0.2 & $21 \cdot 6$ & 0.16 & $19 \cdot 9^{*}$ & 0.21 & $21.8 \dagger$ & 0.15 \\
\hline & 120 & $23 \cdot 2$ & 0.3 & $22 \cdot 8$ & 0.28 & $21 \cdot 1^{*}$ & 0.26 & $22 \cdot 7 \dagger$ & 0.15 \\
\hline & 150 & $24 \cdot 1$ & 0.2 & $24 \cdot 2$ & 0.12 & $23 \cdot 6^{*}$ & 0.14 & 23.9 & 0.21 \\
\hline \multirow[t]{5}{*}{$\mathrm{BMI}\left(\mathrm{g} / \mathrm{cm}^{2}\right)$} & 30 & 0.39 & 0.004 & 0.40 & 0.01 & $0.27^{\star}$ & 0.01 & 0.31 & 0.004 \\
\hline & 60 & 0.63 & 0.01 & 0.67 & 0.01 & $0.56^{*}$ & 0.01 & 0.59 & 0.01 \\
\hline & 90 & 0.78 & 0.01 & 0.76 & 0.02 & $0.62^{*}$ & 0.02 & $0.74 \dagger$ & 0.01 \\
\hline & 120 & 0.74 & 0.01 & 0.76 & 0.01 & $0.63^{*}$ & 0.01 & $0.70 \dagger$ & 0.01 \\
\hline & 150 & 0.74 & 0.02 & 0.75 & 0.01 & $0.67^{\star}$ & 0.01 & 0.70 & 0.01 \\
\hline Abdominal circumference $(\mathrm{cm})$ & 150 & $17 \cdot 7$ & 0.2 & $17 \cdot 6$ & 0.2 & $18 \cdot 6^{\star}$ & 0.5 & $17.5 \dagger$ & 0.2 \\
\hline
\end{tabular}

$\mathrm{NT}_{\mathrm{p}}$, pups of untrained rats; $T_{p}$, pups of trained rats; $\mathrm{NT}+\mathrm{LP}_{\mathrm{p}}$, pups of untrained rats with a low-protein diet; $T+L P_{p}$, pups of trained rats with a low-protein diet; \%BWG, percentage of body-weight gain.

* Mean values were significantly different from the $\mathrm{NT}_{\mathrm{p}}$ group $(P<0.05$; two-way ANOVA).

$\dagger$ Mean values were significantly different from the NT $+\operatorname{LP}_{\mathrm{p}}$ group $(P<0.05$; two-way ANOVA).

$\ddagger$ During gestation, the dams were subjected to physical training and fed a low-protein diet. During lactation, the dams continued to receive a low-protein diet. 


\section{Results}

Before mating, there was no difference between the groups in terms of body weight ( $P>0 \cdot 05)$. During gestation, moderate physical training attenuated the effects of a low-protein diet as reflected by the mother diet-training interaction for this analysis $\left(F_{6,36}=4.757, P<0.0001\right)$. Actually, the effects of a low-protein diet on BWG during gestation were seen at the third week of gestation in the untrained dams (NT + LP), while in the T + LP dams, these effects were normalised (Fig. 1(a) and (b)). Data were adjusted for the number of pups born to each dam (NT, median 11.0 (minimum-maximum 9-13); $\mathrm{T}$, median 11.5 (minimum-maximum 9-14); NT + LP, median 10.5 (minimum-maximum 8-11); $\mathrm{T}+\mathrm{LP}$, median 11.0 (minimum-maximum 9-12)). Pearson's correlation coefficient between the number of pups and the mother's BWG was not significant $\left(r^{2} 0 \cdot 27, P=0 \cdot 452\right)$. Relative daily food intake during gestation was not different between the groups $\left(F_{6,36}=0.423, \quad P=0.85\right.$; Fig. $\left.1(\mathrm{c})\right)$. Fasting blood glucose only changed in the NT + LP mother group, which displayed greater values compared with the NT + LP group $\left(F_{6,36}=2.316, P<0.05\right.$; Fig. $\left.1(\mathrm{~d})\right)$.

Pups from mothers subjected to physical training before and during gestation and/or to a low-protein diet during gestation were evaluated from birth to $150 \mathrm{~d}$. Pups from mothers subjected to physical training showed a less pronounced reduction in body weight, body length and BMI especially in the interval between 60th and 120th day old, with a significant mother diet-physical training interaction $\left(F_{4,50}=7 \cdot 439\right.$, $P<0.001$; Table 1). In addition, at the 150th day of life, the NT $+\mathrm{LP}_{\mathrm{p}}$ animals displayed a greater abdominal circumference than the $\mathrm{NT}_{\mathrm{p}}$ animals that was attenuated in the $\mathrm{T}+\mathrm{LP}$ pups (Table 1).

From 145-147 d old, pups were subjected to the GTT and ITT. There were no differences between the groups on the GTT and ITT curves (Fig. 2(a) and (c)); however, areas under the glycaemic curve were greater in the $\mathrm{NT}+\mathrm{LP}_{\mathrm{p}}$ group than in the $\mathrm{NT}_{\mathrm{p}}$ group (Fig. 2(b)). The rate of disappearance of glucose was lower in the $\mathrm{NT}+\mathrm{LP}_{\mathrm{p}}$ animals (Fig. 2(d)). The effects of the maternal low-protein diet were attenuated in response to physical training $\left(\mathrm{T}+\mathrm{LP}_{\mathrm{p}}\right)$ (mother diet-physical training interaction: $F_{15,245}=20 \cdot 21$, $P<0 \cdot 001)$.

At $150 \mathrm{~d}$ old, the $\mathrm{NT}+\mathrm{LP}_{\mathrm{p}}$ animals showed greater fasting glycaemia and cholesterolaemia when compared with the $\mathrm{NT}_{\mathrm{p}}$ group. However, in the $\mathrm{T}+\mathrm{LP}_{\mathrm{p}}$ animals, glycaemia (NT : mean 91.1 (SEM 1.6); $\mathrm{T}_{\mathrm{p}}$ : mean $98.0($ SEM $2 \cdot 1)$; $\mathrm{NT}+\mathrm{LP}_{\mathrm{p}}$ : mean 108.4 (SEM 2.0); T $+\mathrm{LP}_{\mathrm{p}}$ : mean 91.3 (SEM 3.8)) and cholesterolaemia ( $\mathrm{NT}_{\mathrm{p}}$ : mean 153.3.1 ( $\mathrm{SEM} 0 \cdot 6$ ); $\mathrm{T}_{\mathrm{p}}$ : mean 156.0 (SEM 1.4); NT + LP $\mathrm{p}_{\mathrm{p}}$ : mean 172.1 (SEM 1.3); T + LP mean 164.1 (SEM 0.9)) were normalised $\left(F_{3,56}=5 \cdot 145\right.$, $P=0.003$; Fig. 3).

Leptin content in the soleus muscle was greater $(+45 \%)$ in the $\mathrm{NT}+\mathrm{LP}_{\mathrm{p}}$ pups in comparison with the $\mathrm{NT}_{\mathrm{p}}$ group. Conversely, leptin content was lower in pups from trained mothers $\left(\mathrm{T}+\mathrm{LP}_{\mathrm{p}}-48 \%\right)$ in comparison with the $\mathrm{NT}+\mathrm{LP}_{\mathrm{p}}$ pups, with a significant mother diet-physical training interaction $\left(F_{3,58}=3.967, P<0 \cdot 05\right)$. Plasma leptin concentrations were lower in the $\mathrm{NT}+\mathrm{LP}_{\mathrm{p}}$ animals when compared with the $\mathrm{NT}_{\mathrm{p}}$ group, and physical training was not able to attenuate this effect $\left(\mathrm{NT}_{\mathrm{p}}\right.$ : mean $4.4(\operatorname{sEm} 1 \cdot 3) ; \mathrm{NT}+\mathrm{LP}_{\mathrm{p}}$ : mean $1 \cdot 8(\operatorname{sem~} 0 \cdot 1) ; \mathrm{T}+\mathrm{LP}_{\mathrm{p}}$ : mean $1 \cdot 3(\operatorname{sem~} 0 \cdot 1)$; Fig. 4 ).

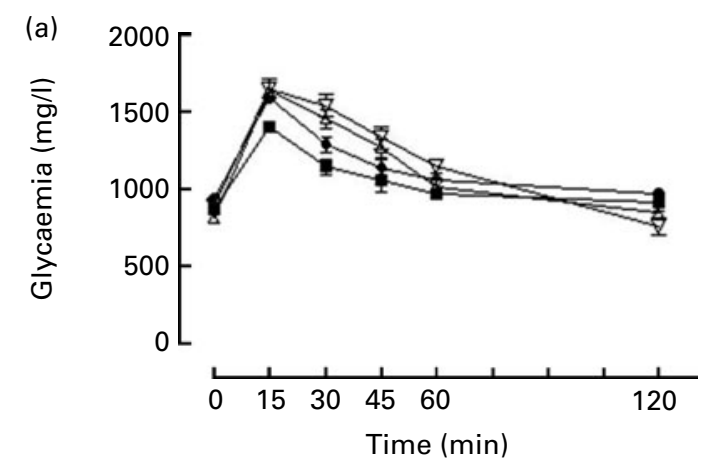

(b)
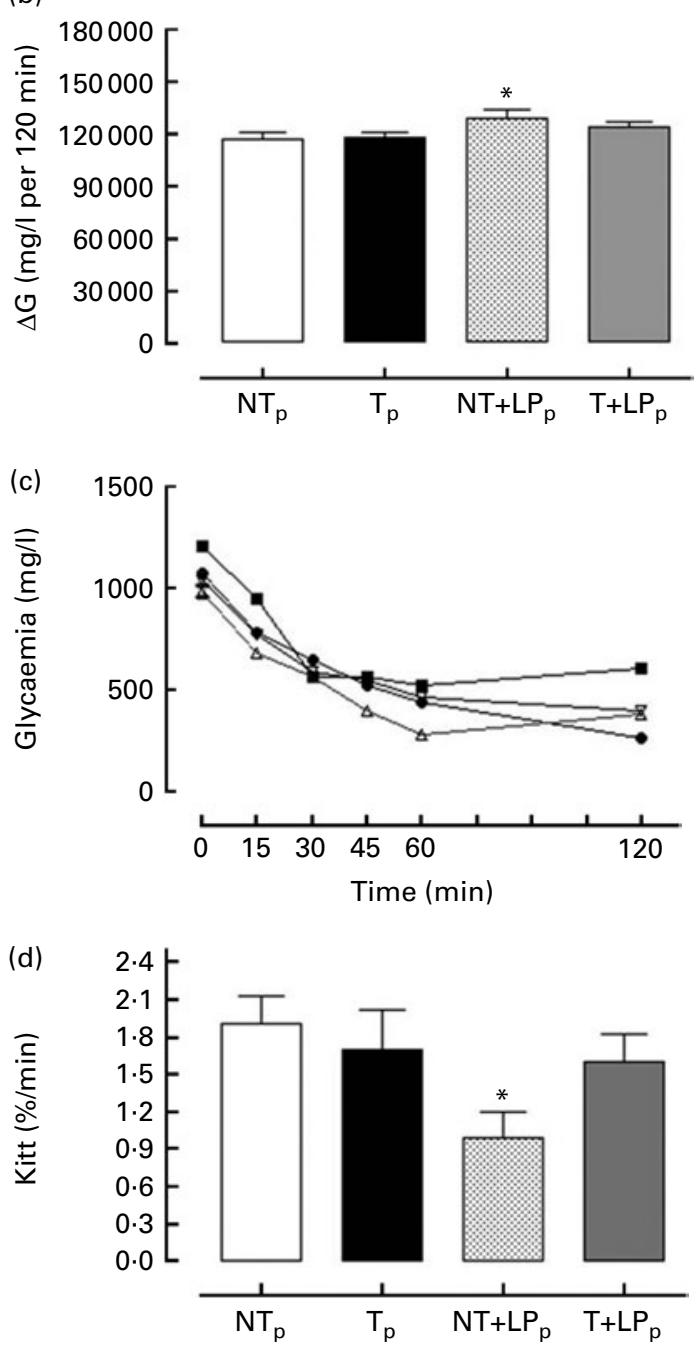

Fig. 2. (a) Glucose tolerance test, (b) areas under glycaemic curve, (c) insulin tolerance test and (d) rate of disappearance of glucose 'Kitt' of offspring at 145-147 d old from untrained $\left(\mathrm{NT}_{\mathrm{p}}, n 8 ;(\mathrm{a}, \mathrm{c})-\mathrm{-}\right)$, trained $\left(\mathrm{T}_{\mathrm{p}}, n 8 ;(\mathrm{a}, \mathrm{c})\right.$ -) , untrained + low-protein (NT + LP,$n$ 8; (a, c) $\triangle$ ) and trained + lowprotein mothers $\left(T+\mathrm{LP}_{\mathrm{p}}, n 8 ;(\mathrm{a}, \mathrm{c}) \nabla\right)$. Values are means with their standard errors represented by vertical bars. * Mean values were significantly different from the $\mathrm{NT}_{\mathrm{p}}$ group $(P<0.05$; two-way ANOVA). 


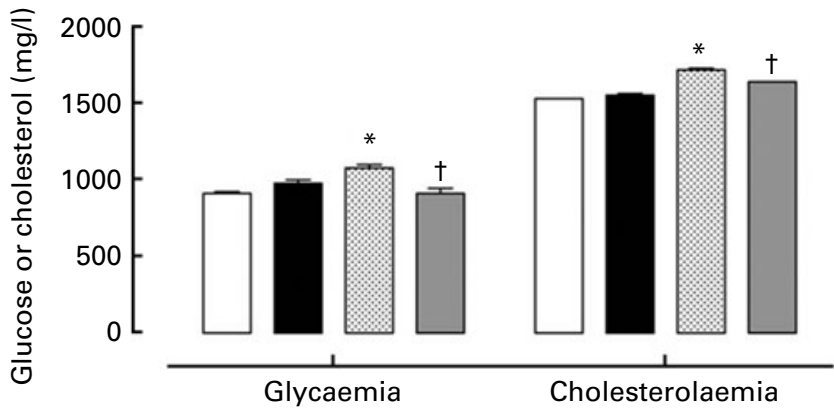

Fig. 3. Fasting blood glucose and cholesterol of the offspring at $150 \mathrm{~d}$ old from untrained $\left(\mathrm{NT}_{\mathrm{p}}, n\right.$ 8; $\left.\mathrm{\square}\right)$, trained $\left(\mathrm{T}_{\mathrm{p}}, n\right.$ 8; $\left.\mathbf{\square}\right)$, untrained + low-protein $\left(\mathrm{NT}+\mathrm{LP}_{\mathrm{p}}, n\right.$ 8; 圆) and trained + low-protein mothers $\left(\mathrm{T}+\mathrm{LP}_{\mathrm{p}}, n\right.$ 8; $\left.\square\right)$. Values are means with their standard errors represented by vertical bars. * Mean values were significantly different from the NT group $(P<0.05$; twoway ANOVA). † Mean values were significantly different from the NT + LP group $(P<0.05$; two-way ANOVA)

\section{Discussion}

An active maternal lifestyle, including regular physical activity and moderate physical training, improves aerobic fitness and the maternal-fetal physiological reserve and, thus, enhances nutrient and oxygen delivery to the fetus ${ }^{(11)}$. In the mother, improved cardiovascular function, limited BWG and a reduced risk of gestational diabetes mellitus and gestational hypertension have been observed ${ }^{(20)}$. For the fetus, reduced fat mass, high tolerance to stress and an advanced neurobehavioural maturation have been observed ${ }^{(20)}$. Our previous studies using animal models have shown that maternal physical training on a treadmill $(5 \mathrm{~d} /$ week, progressive reduction in duration and intensity $50-20 \mathrm{~min} / \mathrm{d}, 65-30 \% \mathrm{VO}_{2 \max }$ ) resulted in reduced BWG and high resting oxygen consumption (resting $\mathrm{VO}_{2}$ ) and attenuated the delayed reflex ontogeny induced by undernutrition ${ }^{(9,21)}$. The present study has evaluated the long-term effects of a maternal moderate-low physical training protocol on BWG, glucose homeostasis and leptin concentration in adult offspring whose mothers were subjected to a low-protein diet during the perinatal period.

In the present study, although trained mothers demonstrated increased body-weight gain in the second and third weeks of gestation, the food intake did not differ, with the exception of the $\mathrm{T}+\mathrm{LP}_{\mathrm{p}}$ animals. The present results are in agreement with previous studies ${ }^{(9,21)}$. Because physical training can induce an increase in maternal lean body mass ${ }^{(13)}$, it may be inferred that body weight is increased by a mechanism that includes an increase in the synthesis of muscle proteins ${ }^{(9)}$. In dams, physical training was also able to normalise the effects of a low-protein diet on fasting serum glucose. This differential effect observed in previously active compared with undernourished dams may be related to reductions in the risk of gestational diabetes mellitus, as an exercise programme may improve insulin sensitivity and fasting plasma glucose concentrations of women at risk for gestational diabetes $^{(22)}$.

Low-protein diet offspring remained growth retarded throughout life and maintained a greater abdominal circumference, even when fed the control diet ad libitum from weaning to adult life. The present results are in agreement with previous studies that have indicated that pups from undernourished mothers experienced a reduced postnatal growth trajectory $^{(9,23-25)}$. Several hormonal changes, including greater leptin and $\mathrm{T} 3$ and lower serum insulin-like growth factor concentrations, are associated with malnutrition during gestation and lactation and can be possible imprinting factors in the growth and development programming of the progeny ${ }^{(26)}$. Maternal physical training had beneficial effects on the postnatal growth rate in offspring from undernourished mothers. The underlying mechanisms of these effects may be related to metabolic changes, redistribution of blood flow and changes in the production of fetal and placental hormones that control growth ${ }^{(9)}$. The insulin-like growth factor and their associated binding proteins are thought to be an important mechanism underlying the long-term effects of maternal physical training ${ }^{(27)}$. Treadmill exercise $(20 \mathrm{~m} / \mathrm{min}, 20 \mathrm{~min} / \mathrm{d}$, during $19 \mathrm{~d}$ ) results in an increase in the plasma concentration of growth hormone, insulin-like growth factor I and insulinlike growth factor binding protein-3 in the late period of pregnancy ${ }^{(27)}$. Nevertheless, these effects are directly dependent on the volume of effort (duration and intensity), and opposite
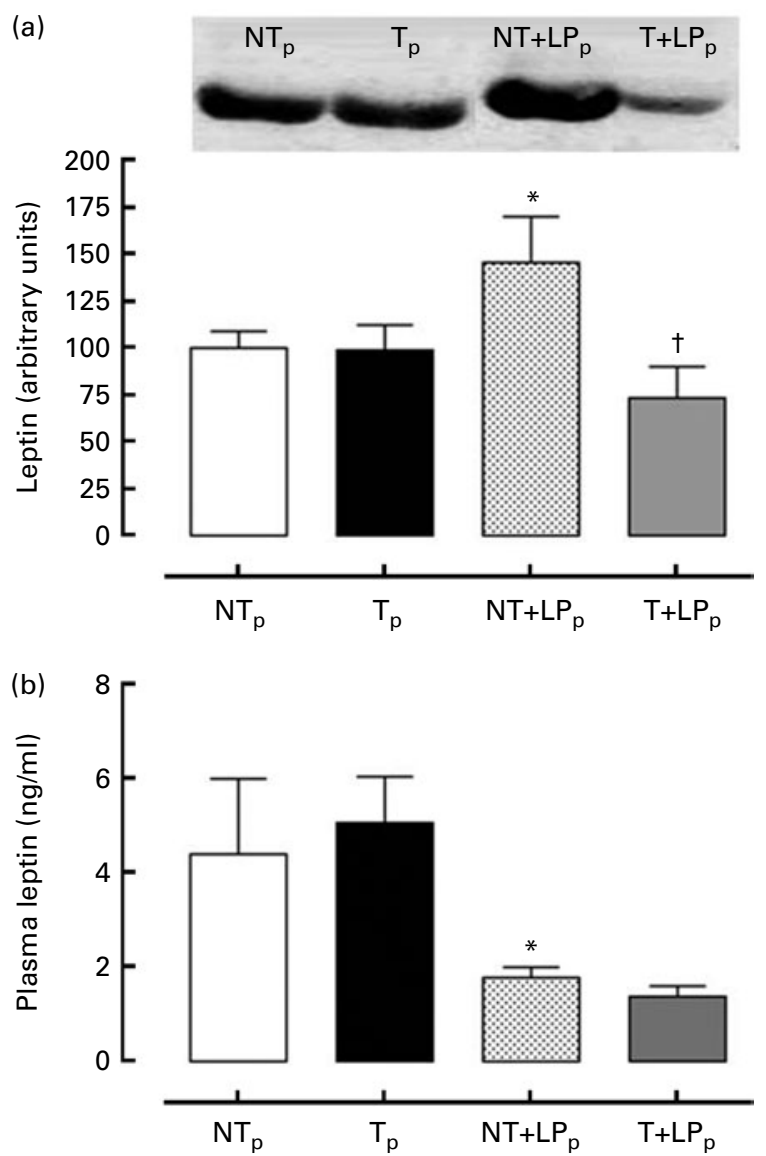

Fig. 4. (a) Leptin in the soleus muscle and (b) plasma leptin of the offspring at $150 \mathrm{~d}$ old from untrained $\left(\mathrm{NT}_{\mathrm{p}} ; n 8\right)$, trained $\left(\mathrm{T}_{\mathrm{p}} ; n 8\right)$, untrained + low-protein $\left(\mathrm{NT}+\mathrm{LP}_{\mathrm{p}} ; n\right.$ 8) and trained + low-protein mothers $\left(\mathrm{T}+\mathrm{LP}_{\mathrm{p}} ; n\right.$ 8). Values are means with their standard errors represented by vertical bars. * Mean values were significantly different from the NT group $(P<0.05$; twoway ANOVA). † Mean values were significantly different from the NT + LP group ( $P<0.05$; two-way ANOVA). 
effects are observed in high-intensity exercise during pregnancy ${ }^{(28)}$. In the present study, the intensity and duration of each session of exercise was controlled in order to keep the effort approximately $65-30 \%$ of $\mathrm{VO}_{2 \max }$. Thus, positive effects on offspring growth are observed when undernourished dams are subjected to moderate-low physical training.

In the present study, a perinatal low-protein diet induced greater glycaemia and cholesterolaemia, a greater area under the glucose curve and a reduced rate of disappearance of glucose than observed in their pairs. The present results confirm those presented in previous studies ${ }^{(25,29)}$. It is interesting to note that physical training attenuated the deleterious effects of perinatal undernutrition. These observations indicate that maternal physical exercise initiated in early pregnancy induces feto-placental adaptations and can be considered as a therapeutic means of countering the effects of maternal undernutrition, which may provide a useful strategy for enhancing nutrient and oxygen availability to the fetus. The underlying mechanism can be related to epigenetic modulation induced by physical activity that regulates gene expression $^{(30)}$. For example, it has been found that physical exercise induces the DNA methylation of brain neurotrophic factors (BDNF-IV), increases the concentration of protein involved in DNA methylation and mRNA, and increases the acetylation of histones ${ }^{(30)}$. In the case of these changes occurring during the critical period of fetal development, physical activity assumes an important role in the control of gene transcription in the context of the long-term effects of developmental plasticity. According to advances in the studies of the Developmental Origin of Health and Disease and epigenomic factors, physical activity during gestation opens new therapeutic possibilities for low-cost treatment for disorders associated with perinatal undernutrition.

In the present study, leptin concentrations were evaluated in the plasma and skeletal muscle. We have observed that protein restriction during gestation and lactation induced a reduced plasma leptin concentration at $150 \mathrm{~d}$ of age. In contrast, previous studies in which dams were subjected to undernutrition during lactation have indicated that adult offspring developed greater leptinaemia and central leptin resistance with increased total $(39 \%)$ and visceral fat mass $(2.3 \text { times })^{(31,32)}$. Different periods early in life to induce undernutrition appear to be crucial in the long-term effects of plasma leptin concentrations. Maternal physical training was not able to normalise the effects of maternal low-protein diet. Thus, a maternal low-protein diet during gestation and lactation seems to affect the synthesis and metabolism of leptin, and also causes the effects on their receptors that persist long after the subsequent normalisation of nutrition ${ }^{(33)}$.

Leptin is mainly produced by the adipocyte; however, it is also produced by several other tissues, including skeletal muscle $^{(7)}$, where its expression may be different from that produced in the adipocyte. In the present study, the $\mathrm{NT}+\mathrm{LP}_{\mathrm{p}}$ animals experienced an increase in the expression of leptin in the skeletal muscle. Leptin in the muscle could be indicative of adipocyte infiltration or may be due to leptin produced directly by the muscle fibres ${ }^{(34)}$. The dissociation of leptin serum levels and muscle leptin content in the $\mathrm{NT}+\mathrm{LP}_{\mathrm{p}}$ group may be explained by the fact that leptin serum levels are associated with adipose tissue mass, and the muscle contribution to plasma leptin levels may not be important. The importance of leptin muscle content may be on the control of local glucose homeostasis, as it has already been shown that intramuscular fat is associated with insulin resistance ${ }^{(34)}$. With training, this supposed adipocyte infiltration may decrease, thereby normalising leptin intramuscular production.

The primary aim of the present study was to test the hypothesis that moderate physical training before and during gestation attenuates the effects of perinatal low-protein undernutrition. Indeed, the effects of a perinatal low-protein diet on the development, glucose homeostasis and leptin concentrations in the skeletal muscle of the offspring were attenuated in pups from trained mothers.

\section{Acknowledgements}

The authors are indebted to Lucia Pires and Edeones França for their technical assistance. This study was supported by the Foundation for Support of Science and Research in Pernambuco State, Brazil (FACEPE), Coordination for the Improvement of Higher Level Personnel (PROCAD-Capes) and the National Council for Research, Brazil (CNPq). The authors' contributions are as follows: M. F. and C. G. L. performed the study design; F. F.-T., A. B.-S., E. O., J. F. N.-N. and M. F. performed the experiments and data collection; M. F., R. M. C. and C. G. L. performed the statistical analyses, interpreted the data and wrote the manuscript; M. F., P. C. L., E. G. M. and C. G. L. were responsible for critical revisions to the manuscript, and all authors approved the final version. The authors declare that there are no conflicts of interest. M. F. and C. G. L. declare that all authors listed are eligible for authorship.

\section{References}

1. Hanson MA \& Gluckman PD (2005) Developmental processes and the induction of cardiovascular function: conceptual aspects. J Physiol 565, 27-34.

2. Barker DJ (2007) The origins of the developmental origins theory. J Intern Med 261, 412-417.

3. Gluckman PD \& Hanson MA (2004) Living with the past: evolution, development, and patterns of disease. Science 305, 1733-1736.

4. Hanson M, Godfrey KM, Lillycrop KA, et al. (2011) Developmental plasticity and developmental origins of non-communicable disease: theoretical considerations and epigenetic mechanisms. Prog Biophys Mol Biol 106, 272-280.

5. Ozanne SE \& Hales CN (2004) Lifespan: catch-up growth and obesity in male mice. Nature 427, 411-412.

6. Zambrano E, Bautista CJ, Deas M, et al. (2006) A low maternal protein diet during pregnancy and lactation has sex- and window of exposure-specific effects on offspring growth and food intake, glucose metabolism and serum leptin in the rat. J Physiol 571, 221-230.

7. Wang J, Liu R, Hawkins M, et al. (1998) A nutrient-sensing pathway regulates leptin gene expression in muscle and fat. Nature 393, 684-688.

8. Trevenzoli IH, Rodrigues AL, Oliveira E, et al. (2010) Leptin treatment during lactation programs leptin synthesis, 
intermediate metabolism, and liver microsteatosis in adult rats. Horm Metab Res 42, 483-490.

9. Amorim MF, dos Santos JA, Hirabara SM, et al. (2009) Can physical exercise during gestation attenuate the effects of a maternal perinatal low-protein diet on oxygen consumption in rats? Exp Physiol 94, 906-913.

10. Clapp JF 3rd, Kim H, Burciu B, et al. (2002) Continuing regular exercise during pregnancy: effect of exercise volume on fetoplacental growth. Am J Obstet Gynecol 186, 142-147.

11. Clapp JF 3rd (2003) The effects of maternal exercise on fetal oxygenation and feto-placental growth. Eur J Obstet Gynecol Reprod Biol 110, Suppl. 1, S80-S85.

12. ACOG Committee Obstetric Practice (2002) ACOG Committee opinion. Number 267, January 2002: exercise during pregnancy and the postpartum period. Int $J$ Gynaecol Obstet 77, 79-81.

13. Leandro CG, Levada AC, Hirabara SM, et al. (2007) A program of moderate physical training for Wistar rats based on maximal oxygen consumption. J Strength Cond Res 21, $751-756$

14. Hatch MC, Shu XO, McLean DE, et al. (1993) Maternal exercise during pregnancy, physical fitness, and fetal growth. Am J Epidemiol 137, 1105-1114.

15. Bayne K (1996) Revised guide for the care and use of laboratory animals available. American Physiological Society. Physiologist 39, 208-111.

16. Reeves PG, Nielsen FH \& Fahey GC Jr (1993) AIN-93 purified diets for laboratory rodents: final report of the American Institute of Nutrition $\mathrm{Ad} \mathrm{Hoc}$ Writing Committee on the reformulation of the AIN-76A rodent diet. J Nutr 123, 1939-1951.

17. Lopes de Souza S, Orozco-Solis R, Grit I, et al. (2008) Perinatal protein restriction reduces the inhibitory action of serotonin on food intake. Eur J Neurosci 27, 1400-1408.

18. Novelli EL, Diniz YS, Galhardi CM, et al. (2007) Anthropometrical parameters and markers of obesity in rats. Lab Anim 41, 111-119.

19. Le Floch JP, Escuyer P, Baudin E, et al. (1990) Blood glucose area under the curve. Methodological aspects. Diabetes Care 13, 172-175.

20. Melzer K, Schutz Y, Boulvain M, et al. (2010) Physical activity and pregnancy: cardiovascular adaptations, recommendations and pregnancy outcomes. Sports Med 40, 493-507.

21. Falcão-Tebas F, Bento-Santos A, Fidalgo MA, et al. (2012) Maternal low-protein diet-induced delayed reflex ontogeny is attenuated by moderate physical training during gestation in rats. BrJ Nutr 107, 372-377.

22. Oostdam N, van Poppel MN, Eekhoff EM, et al. (2009) Design of FitFor2 study: the effects of an exercise program on insulin sensitivity and plasma glucose levels in pregnant women at high risk for gestational diabetes. BMC Pregnancy Childbirth 9, 1

23. Desai M, Crowther NJ, Ozanne SE, et al. (1995) Adult glucose and lipid metabolism may be programmed during fetal life. Biochem Soc Trans 23, 331-335.

24. Ozanne SE \& Hales CN (1999) The long-term consequences of intra-uterine protein malnutrition for glucose metabolism. Proc Nutr Soc 58, 615-619.

25. Ozanne SE \& Hales CN (2002) Early programming of glucose-insulin metabolism. Trends Endocrinol Metab 13, $368-373$.

26. Moura EG, Santos RS, Lisboa PC, et al. (2008) Thyroid function and body weight programming by neonatal hyperthyroidism in rats - the role of leptin and deiodinase activities. Horm Metab Res 40, 1-7.

27. Turgut S, Kaptanoglu B, Emmungil G, et al. (2006) Increased plasma levels of growth hormone, insulin-like growth factor (IGF)-I and IGF-binding protein 3 in pregnant rats with exercise. Tohoku J Exp Med 208, 75-81.

28. Hopkins SA, Baldi JC, Cutfield WS, et al. (2010) Exercise training in pregnancy reduces offspring size without changes in maternal insulin sensitivity. J Clin Endocrinol Metab 95, 2080-2088.

29. Ozanne SE, Jensen CB, Tingey KJ, et al. (2005) Low birthweight is associated with specific changes in muscle insulinsignalling protein expression. Diabetologia 48, 547-552.

30. Gomez-Pinilla F, Zhuang Y, Feng J, et al. (2011) Exercise impacts brain-derived neurotrophic factor plasticity by engaging mechanisms of epigenetic regulation. Eur J Neurosci 33, 383-390.

31. de Oliveira Cravo C, Teixeira CV, Passos MC, et al. (2002) Leptin treatment during the neonatal period is associated with higher food intake and adult body weight in rats. Horm Metab Res 34, 400-405.

32. Bonomo IT, Lisboa PC, Pereira AR, et al. (2007) Prolactin inhibition in dams during lactation programs for overweight and leptin resistance in adult offspring. J Endocrinol 192, 339-344.

33. Lisboa PC, Passos MC, Dutra SC, et al. (2006) Leptin and prolactin, but not corticosterone, modulate body weight and thyroid function in protein-malnourished lactating rats. Horm Metab Res 38, 295-299.

34. Miljkovic-Gacic I, Gordon CL, Goodpaster BH, et al. (2008) Adipose tissue infiltration in skeletal muscle: age patterns and association with diabetes among men of African ancestry. Am J Clin Nutr 87, 1590-1595. 